\title{
Distribution of Protein Gene Product 9.5-Immunopositive and NADPH-Diaphorase- Positive Neurons in the Common Marmoset (Callithrix jacchus) Accessory Olfactory Bulb
}

\author{
Takayuki NAKAJIMA $^{1)}$, Yoshikuni TANIOKA ${ }^{2)}$ and Kazuyuki TANIGUCHI ${ }^{3) *}$ \\ ${ }^{1)}$ Laboratory of Biomedical Control, Research Institute for Electronic Science, Hokkaido University, Sapporo 060-0812, ${ }^{2}$ The Central \\ Institute for Experimental Animals, 1430 Nogawa, Miyamae, Kawasaki, Kanagawa 216-0001 and ${ }^{3)}$ Laboratory of Veterinary Anatomy, \\ Faculty of Agriculture, Iwate University, 3-18-8 Ueda, Morioka, Iwate 020-8550, Japan
}

(Received 19 May 2003/Accepted 12 August 2003)

\begin{abstract}
The principal center of the accessory olfactory system is the accessory olfactory bulb (AOB). In primates, simians are divided into two groups, New and Old World monkeys, and the AOB is present in only New World monkeys. The common marmoset (Callithrix jacchus) is a species of New World monkey. Although the morphology of the common marmoset AOB has been demonstrated, the distribution patterns of the mitral/tufted and granule cells of the AOB remain unclear. In the present study, therefore, the distribution of the mitral/tufted and granule cells in the common marmoset AOB was examined using two histochemical markers including immunostaining for protein gene product (PGP) 9.5 and NADPH-diaphorase staining. The vomeronasal nerves, gomeruli and mitral/tufted cells showed PGP 9.5-immunoreactivity. The mitral/tufted cells were arranged in only one or two rows along the margin of the glomerular layer to form the mitral/tufted cell layer (MTL). Since the mitral/tufted cells occurred sparsely in the common marmoset, the M TL was illegible. NADPH-diaphorase reactivity was primarily detected in the rostral and caudal areas of the AOB. In these areas, gran ule cells showed NADPH-diaphorase reactivity. Since the granule cells were sparse, the common marmoset AOB displayed less-developed granule cell layer. Although the functional significance of the AOB remains to be solved in the common marmoset, small-sized and lesslaminated AOB may show that sexual behavior of the common marmoset has lesser dependence on the accessory olfactory system. KEY WORDS: accessory olfactory bulb, common marmoset, NADPH-diaphorase, nitric oxide synthase, protein gene product 9.5.
\end{abstract}

The accessory olfactory system appears from amphibian phylogenetically and is thought to be associated with reproductive and sexual behaviors [12]. The principal center of this system is the accessory olfactory bulb (AOB) $[12,26]$. Among mammals, the rodent AOB is well-developed and clearly displays the following five layers: vomeronasal nerve layer (VNL); glomerular layer (GL); mitral/tufted cell layer (MTL); lateral olfactory tract (LOT); and, granule cell layer (GCL) [11, 21]. Although behavioral studies have revealed strong linkage between the accessory olfactory system and reproductive behaviors in rodents [13, 26], this linkage seems to be weak in other animals, including the ewe [2], pig [4] and ferret [9, 24]. In these animals, the $\mathrm{AOB}$ is relatively small in size in spite of the presence of very large main olfactory bulb (MOB) [12]. In animals with a relatively small AOB with a smaller number of neurons, the identification of laminar organization tends to be more difficult than in those with larger AOB [12].

In primates, simians are divided into two groups, New and Old World monkeys, and the AOB is present in only New World monkeys $[12,20]$. The common marmoset (Callithrix jacchus) is a species of New World monkey. Although the morphology of the common marmoset AOB has been demonstrated [19], the distribution patterns of the mitral/tufted and granule cells of the AOB remain unclear.

\footnotetext{
*Correspondence to: Dr. Taniguchi, K., Laboratory of Veterinary Anatomy, Faculty of Agriculture, Iwate University, 3-18-8 Ueda, Morioka, Iwate 020-8550, Japan.
}

To confirm the distribution of the mitral/tufted and granule cells in the common marmoset AOB, we used two histochemical markers in the present study. These histochemical markers are immunostaining for protein gene product (PGP) 9.5, which is predominantly localized in the mitral/ tufted cells in the rodent $[14,22]$ and dogs [15], and staining for NADPH-diaphorase, which is predominantly localized in the granule cells in various animals $[1,3,10,15,16]$.

\section{MATERIALS AND METHODS}

Animals and tissue preparation: Seven adult common marmosets of either sex, weighing 252-386 g were used. They were kept in the Central Institute for Experimental Animals (Kawasaki, Japan), fed and watered ad libitum. The animals were deeply anaesthetized by ketamine ( $30 \mathrm{mg} /$ $\mathrm{kg}$, i.m.) and xylazine ( $2.3 \mathrm{mg} / \mathrm{kg}$, i.m.) and perfused with physiological saline, followed by Bouin's solution without acetic acid for paraffin sections or by $4 \%$ paraformaldehyde-0.1 M phosphate buffer (PB) ( $\mathrm{pH}$ 7.4) for frozen sections. These procedures were carried out according to the Guidelines for Animal Experimentation established by the Japanese Association for Laboratory Animal Science. For paraffin sections, the cerebral hemispheres containing olfactory bulb and olfactory peduncle (OP) were removed from 2 animals, immersed in the fixative for $24-48 \mathrm{hr}$ and embedded in paraffin. Paraffin sections were cut sagittally at 5 $\mu \mathrm{m}$. For frozen sections, the hemispheres containing the 

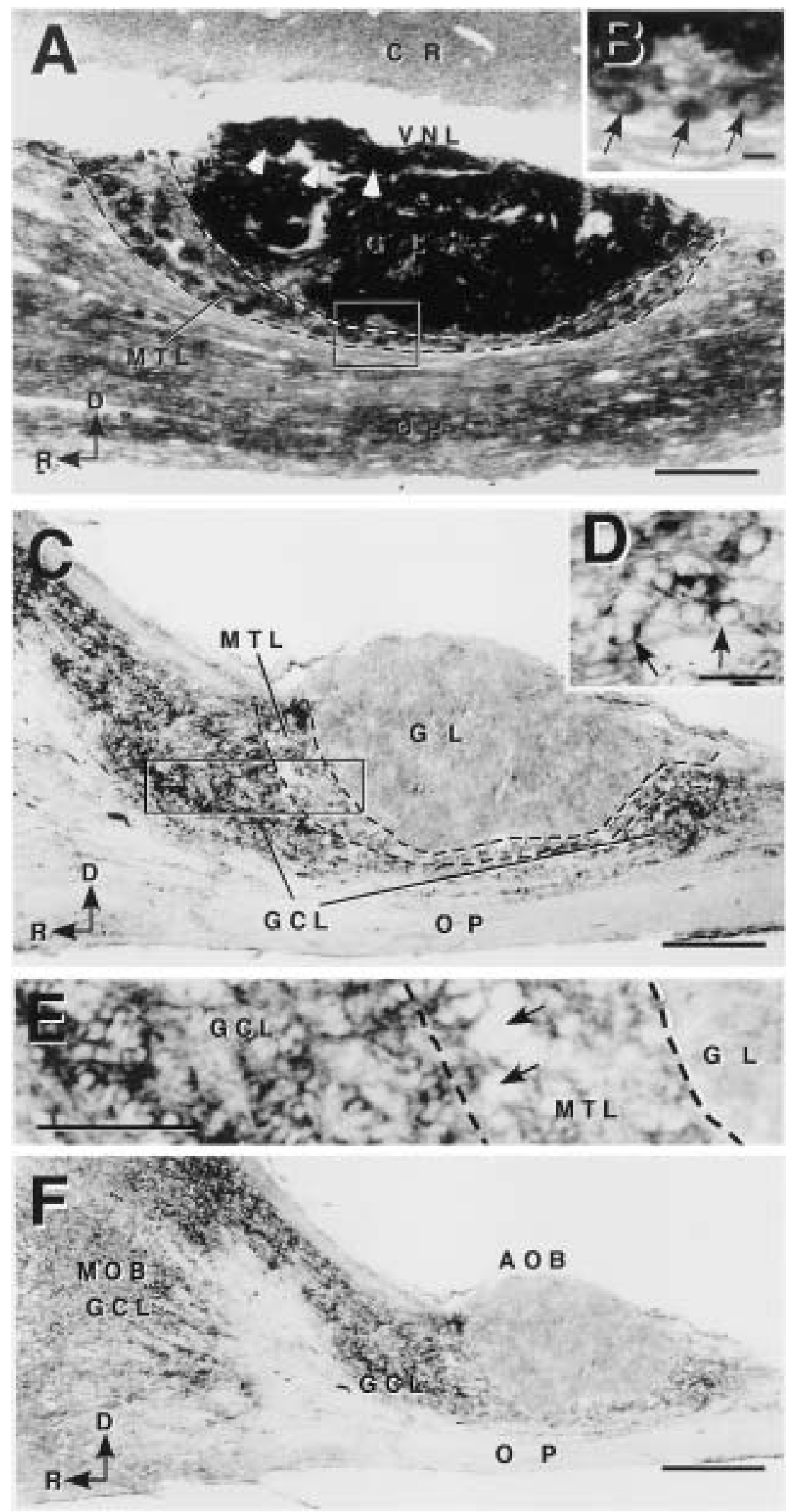
olfactory bulb and the OP were removed from 5 animals, immersed in the fixative for $2-3 \mathrm{hr}$ at $4^{\circ} \mathrm{C}$, and transferred to $30 \%$ sucrose-0.1 M PB (pH 7.4). Frozen sections were cut sagittally at $6-8 \mu \mathrm{m}$ on a cryostat, thaw-mounted on slide glasses coated with 3-aminopropyltriethoxysilane (Shinetsu Chemicals, Tokyo, Japan), and stored at $-20^{\circ} \mathrm{C}$ until use.

Immunohistochemistry for PGP 9.5: Immunohistochemical staining for PGP 9.5 was performed by the avidin-biotin peroxidase complex (ABC) method using a commercial ABC kit (Vector, Burlingame, CA, U.S.A.) and involved following steps: 1) incubation with $10 \%$ normal goat serum at $32^{\circ} \mathrm{C}$ for $30 \mathrm{~min} ; 2$ ) rinse in $0.02 \mathrm{M}$ phosphate buffered saline (PBS) $(\mathrm{pH} \mathrm{7.25)}$ for $15 \mathrm{~min} ; 3)$ incubation with primary rabbit antibody against PGP 9.5 (1:2,000; UltraClone, Wellow, U.K.) at $4^{\circ} \mathrm{C}$ for $48 \mathrm{hr}$; 4) rinse in PBS for $15 \mathrm{~min}$; $5)$ incubation with biotinylated goat anti-rabbit IgG (1:600; Vector) at $32^{\circ} \mathrm{C}$ for $40 \mathrm{~min}$; 6) rinse in PBS for $15 \mathrm{~min}$; 7) incubation with $\mathrm{ABC}$ at $32^{\circ} \mathrm{C}$ for $40 \mathrm{~min} ; 8$ ) rinse in $\mathrm{PBS}$ for $15 \mathrm{~min}$; 9) incubation with $0.05 \mathrm{M}$ tris- $\mathrm{HCl}$ (pH 7.6) containing $0.01 \%$ 3-3' diaminobenzidine tetrahydrochloride (DAB) and $0.003 \%$ hydrogen peroxide for 20-30 min; 10) rinse in distilled water. When the primary antibody was replaced by non-immune rabbit or goat serum, no specific reaction products were observed.

Enzyme-histochemistry for NADPH-diaphorase: Frozen sections were incubated for $60-90 \mathrm{~min}$ at $37^{\circ} \mathrm{C}$ with $1 \mathrm{mM}$ $\beta$-NADPH (Oriental Yeast, Osaka, Japan), $0.1 \mathrm{mM}$ NBT (Wako, Osaka, Japan), and $0.3 \%$ triton X-100 in 0.1 M PB (pH 7.4), rinsed in distilled water and mounted with glycerin jelly. Negative control staining was performed in the absence of $\beta$-NADPH. No specific reaction products were observed in the negative control staining.

Nitric oxide synthase immunohistochemistry/NADPHdiaphorase histochemistry double-staining: First, frozen sections were processed for nitric oxide synthase (NOS) immunohistochemistry. After incubation with the primary rabbit antibody (1:1000; Euro-Diagnostica, Malmö, Sweden), sections were incubated with fluorescein isothyiocyanate (FITC)-conjugated goat anti-rabbit IgG (1:50; Vector) for $2 \mathrm{hr}$ at room temperature to take photographs of selected fields. After photography, the sections were rinsed in PBS and processed for enzyme-histochemistry for NADPH-diaphorase, as described above.

\section{RESULTS}

PGP 9.5-immunoreactivity: The vomeronasal nerve fibers and glomeruli showed strong PGP 9.5-immunoreactivity (Fig. 1A). Since the glomeruli in the commom marmoset AOB were very diffusely organized, the border between the VNL and the GL was illegible. Under the GL, PGP 9.5-immunopositive neurons were observed. These neurons had round or oval somata (11-17 $\mu \mathrm{m}$ in diameter) and were rich in cytoplasm (Fig. 1B). Judging from these morphological features, they were identified as mitral/tufted cells. They occurred sparsely and arranged in one or two rows along the margin of the GL to form the MTL.

NADPH-diaphorase reactivity: NADPH-diaphorase reactivity was primarily detected in the rostral and caudal areas of the AOB (Fig. 1C). In these areas, small-sized neurons $(9-10 \mu \mathrm{m})$ showed NADPH-diaphorase reactivity (Fig. 1D). These neurons were round or oval in shape and meager in cytoplasm. Judging from these morphological features, these neurons were identified as granule cells. They were distributed around NADPH-diaphorase-negative mitral/ tufted cells to form the GCL (Fig. 1E). Since the granule cells were sparse, the common marmoset AOB displayed less-developed GCL.

The parasagittal section of the area containing the caudal part of the MOB, AOB and OP was shown in Fig. 1F by the NADPH-diaphorase staining. There was no significant difference in the intensity of NADPH-diaphorase reactivity in granule cells between the MOB and AOB.

Nitric oxide synthase immunohistochemistry/NADPHdiaphorase histochemistry double-staining: Since NADPHdiaphorase was shown to be NOS in specific neuronal populations of the brain [6], we examined whether the NADPHdiaphorase reactivity in the granule cells was attributed to the NOS. After nitric oxide synthase immunohistochemistry/NADPH-diaphorase histochemistry double-staining, the coincidence between these two reactivities was observed in the granule cells (Fig. 2A, B).

\section{DISCUSSION}

The mitral/tufted cells, the output neurons of the AOB, make synaptic contacts with axons of vomeronasal receptor neurons within the glomeruli [12]. On the other hand, the

Fig. 1. A: PGP 9.5-immunoreactivity in the common marmoset accessory olfactory bulb (AOB). PGP 9.5-immunoreactivity was observed in the vomeronasal nerves (white arrowheads), glomeruli and mitral/tufted cells. Since the glomeruli were very diffusely organized, the border between the vomeronasal nerve layer (VNL) and the glomerular layer (GL) was illegible in the common marmoset. The mitral/ tufted cells were arranged in one or two rows along the margin of the GL to form the mitral/tufted cell layer (MTL). B: Magnific ation of the area squared in A. Arrows indicate PGP 9.5-immunopositive mitral/tufted cells. C: NADPH-diaphorase reactivity in the common marmoset AOB. NADPH-diaphorase reactivity was primarily detected in the rostral and caudal areas of the AOB. D: Arrrows indicates NADPH-diaphorase-positive granule cells. E: Magnification of the area squared in C. NADPH-diaphorase-positive granule cells were distributed around NADPH-diaphorase-negative mitral/tufted cells (arrows) to form the granule cell layer (GCL). F: Low magnification of the area containing the caudal part of the main olfactory bulb (MOB), AOB and olfactory peduncle in the NADPH-diaphorase stained parasagittal section. There was no significant difference in the intensity of NADPH-diaphorase staining between granule cells in the GCL of the MOB and AOB. CR, cerebral cortex; OP, olfactory peduncle; D, dorsal; R, rostral. Scale bars=100 $\mu \mathrm{m}$ (A and C), $10 \mu \mathrm{m}$ (B), $30 \mu \mathrm{m}$ (D), $50 \mu \mathrm{m}(\mathrm{E})$ and $150 \mu \mathrm{m}(\mathrm{F})$. 

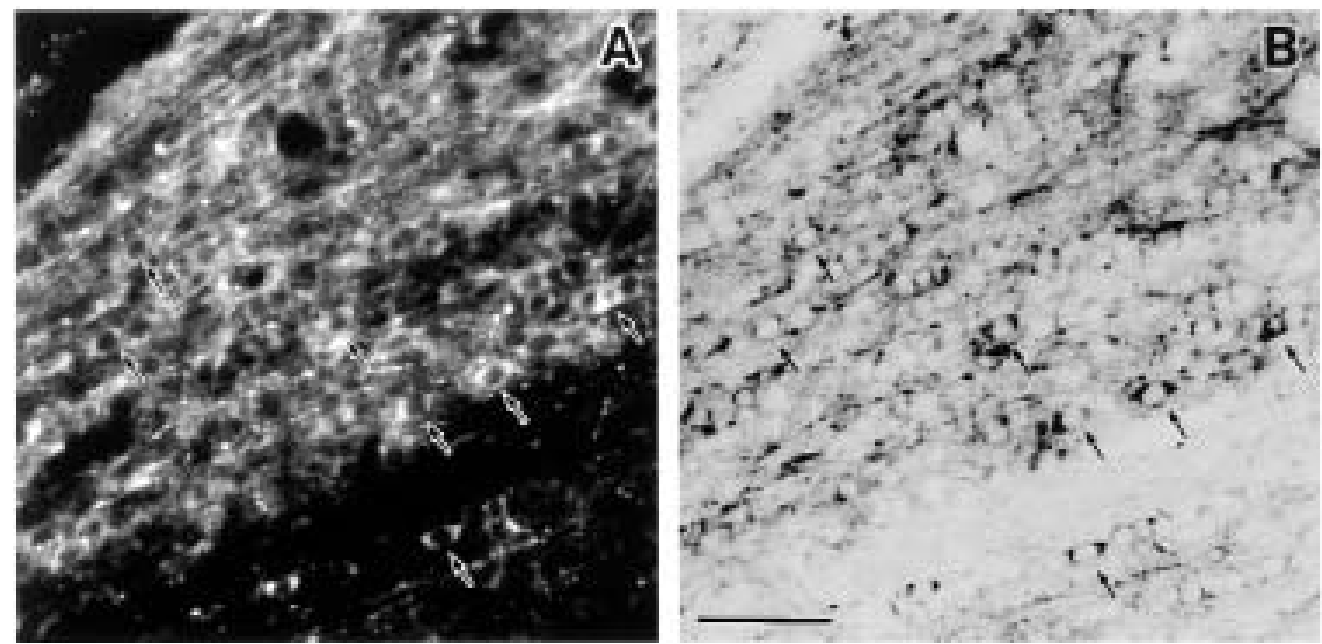

Fig. 2. Nitric oxide synthase (NOS) immunohistochemistry/NADPH-diaphorase histochemistry double-staining. A: NOS-immunopositive granule cells (arrows) of the common marmoset accessory olfactory bulb. B: NADPHdiaphorase-positive granule cells (arrows) in the same field shown in A. Scale bar $=50 \mu \mathrm{m}$.

granule cells, the inhibitory interneurons of the AOB, modulate the excitation of the mitral/tufted cells [12].

Although the AOB has been identified in many mammalian species, the precise position of the AOB was recently demonstrated in the ferret [8] and dog [17]. Since the AOB of the ferret and dog is small in size and different in morphology and the position from the rodents, the AOB of these animals has been overlooked. The recent reports demonstrated the precise position of the dog and ferret AOB using selective histochemical markers for the AOB [8, 17]. In these animals, however, the laminar structure of the AOB often remains to be solved even though the position of the AOB was clearly demonstrated. Salazar et al. [18] tried to demonstrate the distribution of the mitral/tufted cells using monoclonal antibody for neuron specific enolase and neurofilaments but failed to detect the immunoreactivity for these markers in the mitral/tufted cells. On the other hand, we succeeded to demonstrate the mitral/tufted cells of the dog AOB using antibody for PGP 9.5 [15]. PGP 9.5 corresponds to ubiquitin carboxyl terminal hydrolase [5, 25]. PGP 9.5 has been widely used as a neuronal marker in the central and peripheral nervous systems [7, 23]. In the present study, we could reveal the distribution of the mitral/ tufted cells in the common marmoset by means of PGP 9.5immunostaining. The mitral/tufted cells were distributed under the GL to form the MTL. Since the mitral/tufted cells of the common marmoset occurred sparsely and arranged in only one or two rows along the margin of the GL, the MTL was illegible. In the common marmoset AOB, the distribution of granule cells also remained unclear [19]. Since it has been documented that NADPH-diaphorase is localized in the granule cells in various animals $[1,3,10,15,16]$, we conjectured that NADPH-diaphorase staining could reveal the distribution of the granule cells in the common marmoset AOB. In the present study, we observed that the granule cells were distributed under the MTL. Since the granule cells occurred sparsely, the common marmoset AOB displayed less-developed. In the rodent AOB, the granule cells numerously occur to form a well-defined crescent GCL [11]. Since most of the granule cells were concentrated to the rostral and caudal portion of the common marmoset $\mathrm{AOB}$, the present results showed that the GCL in the common marmoset was remarkably different in shape from that in the rodent. Although previous study described that the MTL and the GCL in the common marmoset AOB occurred as one layer containing the mitral/tufted and the granule cells [19], the present results showed that each of the MTL and the GCL was illegible but located apart. Although behavioral studies have revealed strong linkage between the accessory olfactory system and reproductive behaviors in rodents $[13,26]$, the main olfactory system plays an important role in recognition of pheromone in other animals, including the ewe [2], pig [4] and ferret [9, 24]. In these animals, the AOB is relatively small in size in spite of the presence of very large MOB [12]. Although the functional significance of the AOB remains to be solved in the common marmoset, small-sized and less-laminated AOB may show that sexual behavior of the common marmoset has lesser dependence on the accessory olfactory system.

The present nitric oxide synthase immunohistochemistry/ NADPH-diaphorase histochemistry double-staining indicates that NADPH-diaphorase reactivity in the granule cells corresponds to the localization of NOS. In the rodent, NADPH-diaphorase reactivity in the granule cells is stronger in the AOB than in the MOB $[3,10,16]$, suggesting that NOS activity in the granule cells was higher in the AOB than in the MOB in the rodent. In the common marmoset, however, NOS activity in the granule cells of the AOB seemed to be almost the same as that of the MOB judging from the NADPH-diaphorase reactivity. Since the granule 
cells play a role as inhibitory interneurons in the olfactory transduction, these findings may suggest that there is some difference in inhibitory function of the AOB between the common marmoset and rodent.

In conclusion, we revealed the distribution of the mitral/ tufted and granule cells in the common marmoset AOB. PGP 9.5-immunopositive and NADPH-diaphorase-positive neurons were identified as mitral/tufted and granule cells, respectively. Since the mitral/tufted and granule cells occurred sparsely, the common marmoset AOB displayed less-developed MTL and GCL. Although the functional significance of the AOB remains to be solved in the common marmoset, small-sized and less-laminated AOB may show that sexual behavior of the common marmoset has lesser dependence on the accessory olfactory system.

\section{REFERENCES}

1. Alonso, J. R., Arévalo, R., García-Ojeda, E., Porteros, A., Briñón, J. G. and Aijón, J. 1995. NADPH-diaphorase active and calbindin D-28k-immunoreactive neurons and fibers in the olfactory bulb of the hedgehog (Erinaceus europaeus). $J$. Comp. Neurol. 351: 307-327.

2. Cohen-Tannoudji, J., Lavenet, C., Locatelli, A., Tillet, Y. and Signolet, J. P. 1989. Non-involvement of the accessory olfactory system in the LH response of anoestrous ewes to male odour. J. Reprod. Fertil. 86: 135-144.

3. Davis, B. J. 1991. NADPH-diaphorase activity in the olfactory system of the hamster and rat. J. Comp. Neurol. 314: 493-511.

4. Dorries, K. M., Adkins-Regan, E. and Halpern, B. P. 1997. Sensitivity and behavioral response to the pheromone androstenone are not mediated by the vomeronasal organ in domestic pigs. Brain Behav. Evol. 49: 53-62.

5. Hershko, A. and Ciechanover, A. 1992. The ubiquitin system for protein degradation. Annu. Rev. Biochem. 61: 761-807.

6. Hope, B. T., Michael, G. J., Knigge, K. M. and Vincent, S. R. 1991. Neuronal NADPH diaphorase is a nitric oxide synthase. Proc. Natl. Acad. Sci. 88: 2811-2814.

7. Johnson, E. W., Eller, P. M. and Jafek, B. W. 1994. Protein gene product 9.5 in the developing and mature rat vomeronasal organ. Dev. Brain. Res. 78: 259-264.

8. Kelliher, K. R., Baum, M. J. and Meredith, M. 2001. The ferret's vomeronasal organ and accessory olfactory bulb:effects of hormone manipulation in adult males and females. Anat. Rec. 263: $280-288$.

9. Kelliher, K. R., Chang, Y. M., Wersinger, S. R. and Baum, M. J. 1998. Sex difference and testosterone modulation of pheromone-induced neuronal fos in the ferret's main olfactory bulb and hypothalamus. Biol. Reprod. 59: 1454-1463.

10. Kishimoto, J., Keverne, E. B., Hardwick, J. and Emson, P. C. 1993. Localization of nitric oxide synthase in the mouse olfactory and vomeronasal system: a histochemical, immunological and in situ hybridization study. Eur. J. Neurosci. 5: 16841694.

11. Macrides, F. and Davis, B. J. 1983. The olfactory bulb. pp.
391-426. In: Chemical Neuroanatomy (Emson, P. C. ed.), Raven Press, New York.

12. Meisami, E. and Bhatnagar, K. P. 1998. Structure and diversity in mammalian accessory olfactory bulb. Microsc. Res. Tech. 43: 476-499.

13. Meredith, M. 1983. Sensory physiology of pheromone communication. pp. 199-252. In: Pheromone and Reproduction in Mammals (Vandenbergh, J. G. ed.), Academic Press. New York.

14. Nakajima, T., Murabayashi, C., Ogawa, K. and Taniguchi, K. 1998. Immunoreactivity of PGP 9.5 in the developing hamster olfactory bulb. Anat. Rec. 250: 238-244.

15. Nakajima, T., Sakaue, M., Kato, M., Saito, S., Ogawa, K. and Taniguchi, K. 1998. Immunohistochemical and enzyme-histochemical study on the accessory olfactory bulb of the dog. Anat. Rec. 252: 393-402.

16. Porteros, A., Alonso, J. R., Arévalo, R., García-Ojeda, E., Crespo, C. and Aijón, J. 1994. Histochemical localization of NADPH-diaphorase in the rat accessory olfactory bulb. Chem. Senses 19: 413-424.

17. Salazar, I., Barber, P. C. and Cifuentes, J. M. 1992. Anatomical and immunohistological demonstration of the primary neural connections of the vomeronasal organ in the dog. Anat. Rec. 233: $309-313$.

18. Salazar, I., Cifuentes, J. M., Quinteiro, P. S. and Caballero, T. G. 1994. Structural, morphometric and immunohistological study of the accessory olfactory bulb in the dog. Anat. Rec. 240: $277-285$.

19. Sanides-Kohlrausch, C. and Wahle, P. 1990. Morphology of neuropeptide $\mathrm{Y}$-immunoreactive neurons in the cat olfactory bulb and olfactory peduncle: postnatal development and species comparison. J. Comp. Neurol. 291: 468-489.

20. Stephan, H. 1965. Der bulbus olfactorius accessorius bei Insektivoren und Primaten. Acta Anat. 62: 215-253.

21. Takami, S., Fernandez, G. D. and Graziadei, P. P. C. 1992. The morphology of GABA-immunoreactive neurons in the accessory olfactory bulb of rats. Brain Res. 588: 317-323.

22. Taniguchi, K., Saito, H., Okamura, M. and Ogawa, K. 1993. Immunohistochemical demonstration of protein gene product 9.5 (PGP 9.5) in the primary olfactory system of the rat. Neurosci. Lett. 156: 24-26.

23. Thompson, R. J., Doran, J. F., Jackson, P., Dhillon, A. P. and Rode, J. 1983. PGP 9.5-a new marker for vertebrate neurons and neuroendocrine cells. Brain Res. 278: 224-228.

24. Wersinger, S. R. and Baum, M. J. 1997. Sexually dimorphic processing of somatosensory and chemosensory inputs to forebrain luteinizing hormone-releasing hormone neurons in mated ferrets. Endocrinology 138: 1121-1129.

25. Wilkinson, K. D., Lee, K., Deshpande, S., Duerksen-Hughes, P., Boss, J. M. and Pohl, J. 1989. The neuron-specific protein PGP 9.5 is a ubiquitin carboxyl-terminal hydrolase. Science 246: 670-673.

26. Wysocki, C. J. 1979. Neurobehavioural evidence for the involvement of the vomeronasal system in mammalian reproduction. Neurosci. Biobehav. Rev. 3: 301-341. 